\title{
Continuous epidural infusion of morphine versus single epidural injection of extended-release morphine for postoperative pain control after arthroplasty: a retrospective analysis
}

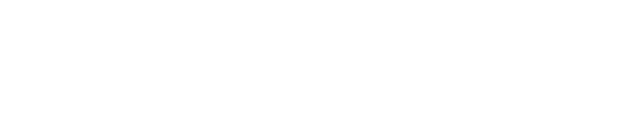

\section{Stephanie Vanterpool \\ Randall Coombs \\ Karamarie Fecho}

Department of Anesthesiology, School of Medicine, University of North Carolina at Chapel Hill, Chapel Hill, NC, USA
Correspondence: Karamarie Fecho University of North Carolina at Chapel Hill, Department of Anesthesiology, CB \#70 I0, Chapel Hill, NC 27599-70I0, USA

Tel $+|919966| 470$

Fax + I 9199664873

Email kfecho@email.unc.edu
Background: This study retrospectively compared the continuous epidural infusion of morphine with a single epidural injection of extended-release morphine for postoperative pain control after arthroplasty.

Methods: Medical records were reviewed for subjects who had total knee or hip arthroplasty (THA) under spinal anesthesia and received either a continuous epidural infusion of morphine (Group EPID; $n=101$ ) or an extended-release epidural morphine (Group EREM; $\mathrm{n}=109$ ) for postoperative pain. Data were collected for three postoperative days (POD) on: pain scores; supplemental opioids; medications for respiratory depression, nausea, and pruritus, and distance ambulated during physical therapy.

Results: Pain scores were similar until subjects were transitioned to another analgesic approach on POD 2; after that time, pain scores increased in Group EPID, although they decreased in Group EREM. Supplemental opioids were used more on POD1 in Group EREM than in Group EPID, although time to first opioid and total daily morphine equivalents were similar. Naloxone and antiemetics, not antipruritics, were used more in Group EREM. Distance ambulated after THA was greater in Group EREM than in Group EPID.

Conclusions: These results suggest that EREM is associated with better postoperative ambulation and analgesia during the transition to oral or intravenous analgesics, although a higher incidence of side-effects was evident.

Keywords: continuous epidural morphine infusion, extended-release epidural morphine, lower extremity arthroplasty, ambulation, postoperative pain, side-effects

\section{Introduction}

Total knee arthroplasty (TKA) and total hip arthroplasty (THA) are considered effective treatments for end-stage joint deterioration due to osteoarthritis or rheumatoid arthritis. ${ }^{1,2}$ Data from the National Hospital Discharge Survey indicates that in the period between 2003-2004, 428,000 knee replacement and 282,000 non-fracture-related hip replacement operations were conducted in the United States, and those numbers are expected to rise as the population ages. ${ }^{3,4}$ Early intense physical therapy is instrumental for postoperative recovery and rehabilitation after both TKA and THA; ${ }^{5,6}$ however, severe postoperative pain often interferes with early physical therapy and decreases patients' quality of life. ${ }^{7}$ The side-effects associated with many analgesic techniques, such as emesis and excessive sedation, can also compromise early physical therapy and rehabilitation. ${ }^{8}$ 
Multiple studies have investigated the effectiveness of different analgesic techniques for lower extremity arthroplasty, including intravenous, regional and neuraxial approaches. ${ }^{1,2} \mathrm{Of}$ the neuraxial modalities, both continuous epidural infusion of morphine and a single epidural injection of extended-release morphine, a lipid encapsulated preparation of morphine, are effective for pain control after TKA and THA. ${ }^{9-13}$ However, few studies have directly compared these two pain management approaches, in terms of pain control, side-effects and ambulation after arthroplasty.

The aim of the present study was to retrospectively compare continuous epidural infusion of morphine with a single epidural injection of extended-release morphine in the 72 hours after THA or TKA. The time period studied included postoperative days 1-2 (POD 1-2), during which time the continuous infusion was in place and the extendedrelease morphine was active, ${ }^{12}$ and POD 3, after patients were transferred to oral or intravenous analgesics; this allowed for an assessment of pain management during the transition of care. The primary outcomes were analgesia, side-effects (respiratory depression, nausea, pruritus) and ambulation.

\section{Materials and methods}

This study was approved by the Institutional Review Board at the University of North Carolina at Chapel Hill.

\section{Study design and subjects}

A retrospective cohort design was used. Medical records were reviewed for 401 subjects who underwent primary unilateral THA or TKA, under the care of the same two surgeons, between May 2005 and April 2006. Medical records were included for further review $(n=210)$ if subjects received subarachnoid bupivacaine as the primary anesthetic, followed by either a continuous epidural infusion of $40 \mu \mathrm{g} / \mathrm{mL}$ morphine with $0.1 \%$ bupivacaine (Group EPID, $\mathrm{n}=101$ ); or a single-dose epidural injection of extendedrelease morphine (DepoDur ${ }^{\circledR}$; EKR Therapeutics, San Diego, CA, USA) (Group EREM, $\mathrm{n}=109$ ) as the primary therapy for postoperative pain management. Other factors, such as the use of supplemental anesthetics, postoperative analgesics, or adjustments in the continuous epidural infusion were not taken into consideration as part of the inclusion process. Medical records were excluded from further review $(n=191)$ if subjects received any other primary form of anesthesia, such as general anesthesia, or any other primary approach to postoperative pain management. The subarachnoid dose of bupivacaine averaged $17.37 \pm 0.53 \mathrm{mg}$ (mean \pm standard error of the mean [SEM]). The epidural infusion rate in Group EPID was dictated by the Acute Pain Service, and the epidural catheter was removed on postoperative day 2 , as per routine postoperative management. The dose of extended-release morphine averaged $11.09 \pm 0.23 \mathrm{mg}$ (mean $\pm \mathrm{SEM}$ ), and was active for up to 48 hours after epidural injection. ${ }^{12}$ Nineteen subjects $(18.8 \%)$ in Group EPID and 3 subjects (2.8\%) in Group EREM were transitioned to intravenous patient-controlled analgesia; the remaining subjects in each group were transitioned to oral or intravenous analgesic boluses.

\section{Primary outcomes and data collection}

Medical records (anesthesia record, post anesthesia care unit [PACU] and floor nursing charts, physical therapy records) were the primary data source. Data were collected on basic demographic and procedural characteristics, including age, sex, height, weight, procedure and indication. Data were then collected with regard to three primary postoperative outcomes: analgesia, side effects, and ambulation. Data were collected on the immediate postoperative period PACU, over PODs 1 and 2, the period during which the continuous EPID and the EREM are active, and for POD 3, after the two groups were transitioned to oral or intravenous analgesia. Data on analgesia were obtained by recording the maximum pain score on an 11-point numerical rating scale (NRS) ranging from 0 (no pain) to 10 (worst pain imaginable) recorded by nurses in the PACU and during each 12-hour nursing shift over POD 1-3. Also data was collected for the use of supplemental opioids (drug, dose, time to first use). Data on side-effects were obtained by recording whether opioid antagonists (naloxone), antiemetics (ondansetron, promethazine) or antipruritics (diphenhydramine, loratadine, nalbuphine) were administered; these measures were used as surrogates for respiratory depression, nausea, and pruritus, respectively. Physical therapy records were used to collect data on the maximum distance ambulated (in feet) over POD 1-3 during daily physical therapy sessions.

\section{Statistical analysis and sample size calculation}

SPSS (version 15; SPSS, Inc. Chicago, IL, USA) was used for statistical analysis and Sigma Plot (version 10; SPSS, Inc.) was used for graphics. For analysis, doses of each supplemental opioid were converted to equivalents of $10 \mathrm{mg}$ intravenous morphine, using the conversion table provided by Gustein and Akil ${ }^{14}$ for hydrocodone, oxycodone and propoxyphene, and the conversion table provided by Dhesi and Hurley ${ }^{15}$ for fentanyl and hydromorphone. The total daily morphine 
equivalents that were administered were calculated for each subject by summation over each postoperative day. Opioid antagonists, antiemetics and antipruritics were treated as binary variables (administered or not administered). NRS pain scores and the distance ambulated were treated as continuous variables. Body mass index (BMI) was calculated treated as a continuous variable. Demographic variables, clinical characteristics, time to first postoperative opioid use and naloxone administration were compared between groups using Chi square analysis (for categorical data) or Student's $t$-test (for continuous variables). Generalized linear models were used to determine if pain scores, side-effects and ambulation differed between groups and over time, with main effects of group and time and a group $\times$ time interaction included in the model. Procedure type (THA or TKA) was included as a covariate in the analysis to control for any difference in outcome between the two groups. A post hoc Fisher's Least Squares Difference test was used to compare group differences at specific time points. The ambulation data were analyzed overall and stratified by type of operation. The data were fairly complete, with pain scores complete for between 187 (89.0\%) and 206 (98.1\%) subjects, and physical therapy notes complete for between 193 (91.9\%) and 203 (96.7\%) subjects, depending on the time point. Data on drug administration were complete for all subjects. The generalized linear model used an estimation algorithm to handle missing data points; the other statistical tests excluded missing variables. The significance level was set at $\alpha=0.05$.

Assuming a 2-point difference ( \pm 2 standard deviations) in the NRS score between Groups EREM and EPID, then to achieve $90 \%$ power, with $\alpha=0.05$, an estimated 22 subjects per treatment group were required, for a total of $n=44$. The incidence of severe postoperative respiratory depression after continuous epidural morphine/bupivacaine is not established, although a 1994 study reported a rate of $0.07 \%$ for cancer patients. ${ }^{16}$ Assuming the true proportion of adverse events for Group EPID is $0.1 \%$ and that for Group EREM is $8 \%,{ }^{9-11}$ then to achieve $80 \%$ statistical power, with $\alpha=0.05$, an estimated 97 subjects per group were required, for a total of 194. Data were collected on 210 subjects in the current study, with 109 in Group EREM and 101 in Group EPID.

\section{Results}

\section{Cohort characteristics}

Groups EPID and EREM were similar with regard to the proportion of females, the average BMI and the proportion of THA and TKA operations (Table 1). Subjects in Group EREM were, however, 6 years older on average, than subjects in Group EPID $(P<0.01$; Table 1$)$.

\section{Analgesia}

Pain scores on arrival to the PACU were low and averaged $0.99 \pm 0.18$ (mean \pm SEM). PACU pain scores did not change over the following two hours and were similar in both Group EPID and Group EREM (data not shown). Pain scores after arrival to the floor (POD 0) and for the morning and afternoon of POD 1 through 3 are shown for Groups EPID and EREM in Figure 1. A significant group $\times$ time interaction $(P<0.01)$ was apparent, meaning that group differences emerged over time. A post hoc analysis showed that pain scores were higher in Group EPID than in Group EREM on the afternoon of POD $2(P<0.05)$, the morning of POD $3(P<0.05)$ and the afternoon of POD 3 $(P<0.07)$. Pain scores did not differ between Group EPID and Group EREM during the period when the epidural catheter was in place and the EREM was active (ie, POD 0 through to the morning of POD 2).

The supplemental IV or oral opioids that were administered to subjects were fentanyl, morphine, hydromorphone, oxycodone, oxycodone/acetaminophen, hydrocodone/ acetaminophen, and propoxyphene/acetaminophen. Time to the first postoperative opioid averaged $112 \pm 9$ minutes (mean \pm SEM) and did not differ between groups. Supplemental postoperative opioid use increased over time in both groups $(P<0.0005$; Figure 2$)$, and a significant group $\times$ time interaction was evident $(P<0.0005)$. A greater proportion of subjects received opioids on POD 1 in Group EREM than in Group EPID $(P<0.0005)$, although a smaller proportion of subjects received opioids on POD 2 and 3 in Group EREM than in Group EPID $(P<0.05$ for POD 2; $P<0.06$ for POD 3$)$. For those subjects that received

Table I Cohort characteristics

\begin{tabular}{llll}
\hline & $\begin{array}{l}\text { Group EPID } \\
(\boldsymbol{n}=\mathbf{I 0 I})\end{array}$ & $\begin{array}{l}\text { Group EREM } \\
(\boldsymbol{n}=\mathbf{1 0 9})\end{array}$ & $\boldsymbol{P}^{\text {value }}{ }^{\mathbf{a}}$ \\
\hline Demographics & & & \\
- Age (years) & $61.26(1.26)$ & $67.12(1.39)$ & $P<0.01$ \\
- Sex-Female & $60(59.4)$ & $75(68.8)$ & N.S. \\
- BMI & $30.21(0.67)$ & $29.01(0.50)$ & N.S. \\
Procedure & & & \\
- Total Hip Arthroplasty & $41(40.6)$ & $55(50.5)$ & N.S. \\
- Total Knee Arthroplasty & $60(59.4)$ & $54(49.5)$ & \\
\hline
\end{tabular}

Notes: aGroups EPID and EREM were compared using Student's t-test or $\mathrm{Ch}$ square analysis. Values are mean ( \pm SEM) or $n(\%)$.

Abbreviations: Group EPID received a continuous epidural infusion of morphine. Group EREM received a single epidural injection of extended-release morphine. SEM, standard error of mean; $n$, number; BMl, body mass index. 


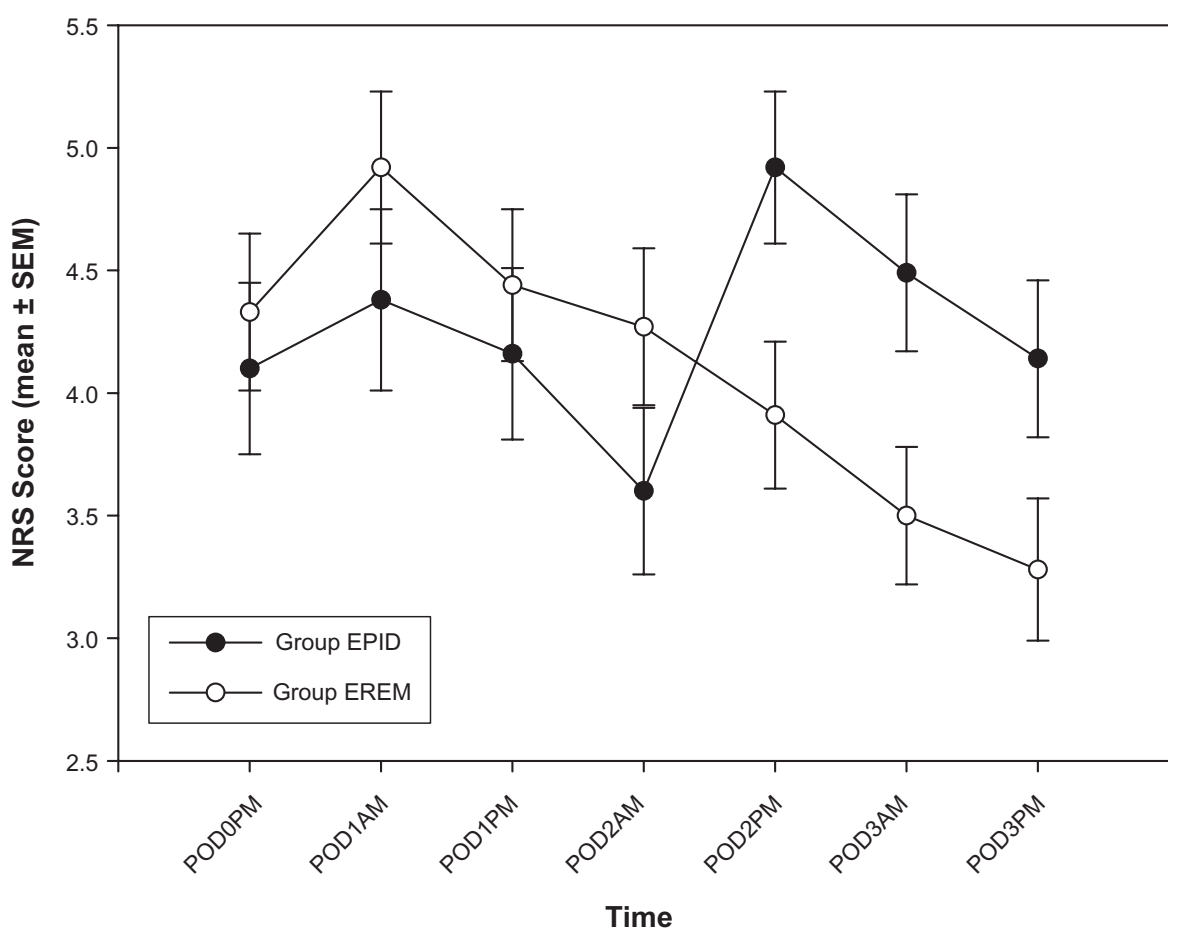

Figure I Pain scores (mean \pm SEM) after lower extremity arthroplasty.

Notes: Pain scores were higher in Group EPID than in Group EREM from POD 2 PM through POD 3 PM (P $<0.05$ for POD 2 PM and POD 3 PM; $P<0.06$ for POD 3 PM). Abbreviations: Group EPID received a continuous epidural infusion of morphine; Group EREM received a single epidural injection of extended-release morphine; PACU: post anesthesia care unit; POD, postoperative day; NRS; numerical rating scale $(0=$ no pain, $10=$ worst pain imaginable).

supplemental opioids, the total daily morphine equivalents that were administered per subject averaged $8.89 \pm 1.12 \mathrm{mg}$ (mean \pm SEM) in the PACU, $16.96 \pm 1.44 \mathrm{mg}$ on POD $0-1,13.61 \pm 0.77 \mathrm{mg}$ on POD 2, and $12.64 \pm 1.01 \mathrm{mg}$ on POD 3. These values did not differ between Groups EPID and EREM.

\section{Side effects}

One subject (1.0\%) in Group EPID received naloxone for respiratory depression, whereas five subjects (4.6\%) in Group EREM received naloxone, although the difference was not significant $(P=0.2)$. Rates of antiemetic use (Figure 3) decreased over time in both groups $(P<0.0005)$. A greater proportion of subjects received antiemetics in the PACU in Group EREM than in Group EPID $(P<0.01)$. Rates of antiemetic use over POD 1-3 did not differ between the two groups.

Rates of antipruritic use (Figure 4) varied over time $(P<0.0005)$, with the highest rates on POD 1. Antipruritic use was similar in Groups EPID and EREM.

\section{Ambulation}

The distance that subjects walked during physical therapy increased over time $(P<0.0005)$ (Figure 5A) and Group EREM showed better ambulation than Group EPID at all time points $(P<0.05)$. However, when subjects were stratified by type of procedure (THA versus TKA), the group difference was found only in the THA subset $(P<0.05$; Figure 5B). For subjects undergoing TKA (Figure 5C), ambulation was similar in Groups EREM and EPID.

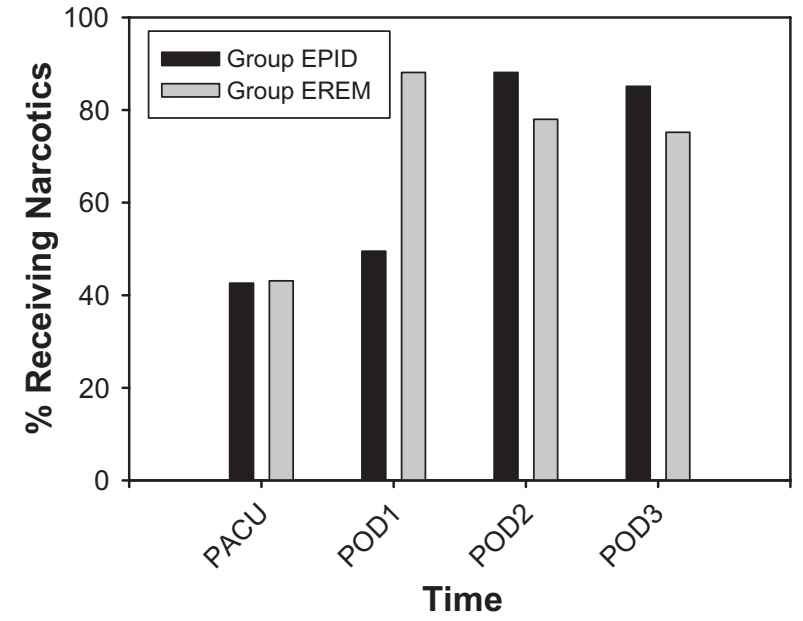

Figure 2 Percentage of subjects receiving postoperative opioids. Notes: A greater proportion of subjects in Group EREM received opioids on POD I than in Group EPID $(P<0.0005)$, although a smaller proportion of subjects in Group EREM received opioids on POD $2(P<0.05)$ and POD $3(P<0.06)$ than in Group EPID.

Abbreviations: Group EPID received a continuous epidural infusion of morphine; Group EREM received a single epidural injection of extended-release morphine; PACU, post anesthesia care unit; POD, postoperative day. 


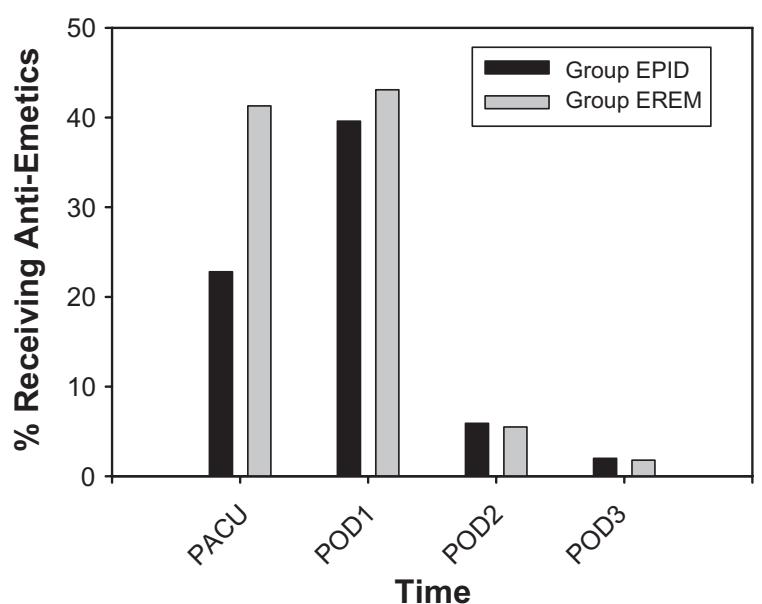

Figure 3 Percentage of subjects receiving postoperative antiemetics.

Notes: A greater proportion of subjects in Group EREM received antiemetics in the PACU than in Group EPID $(P<0.01)$, but the two groups did not differ in antiemetic use over POD I-3.

Abbreviations: Group EPID received a continuous epidural infusion of morphine; Group EREM received a single epidural injection of extended-release morphine; PACU, post anesthesia care unit; POD, postoperative day.

\section{Discussion}

The present study aimed to retrospectively compare continuous epidural infusion of morphine with a single epidural injection of extended-release morphine (DepoDur $^{\circledR}$ ) with regard to postoperative pain control, side-effects and ambulatory function. The time to first postoperative opioid and the total daily morphine equivalents that were administered per subject were similar in the two groups. Postoperative pain scores were also similar in the two groups and decreased over time until patients were transitioned to oral or intravenous analgesics; at which point pain scores increased among subjects who received a continuous epidural infusion of morphine, yet continued to decrease among subjects who received extended-release epidural morphine. Rates of pruritus, as measured by antiemetic administration, were similar in the two groups, although subjects who received extended-release epidural morphine had higher rates of respiratory depression and nausea, as measured by naloxone and antiemetic administration, respectively. Subjects who received extended-release epidural morphine after THA, but not TKA, had better postoperative ambulation than subjects who received a continuous epidural infusion of morphine. Collectively, these results suggest that compared to patients who receive a continuous epidural infusion of morphine for postoperative pain, patients who receive extended-release epidural morphine are more easily transitioned to oral or intravenous analgesics, although they also experience higher rates of nausea and respiratory depression.

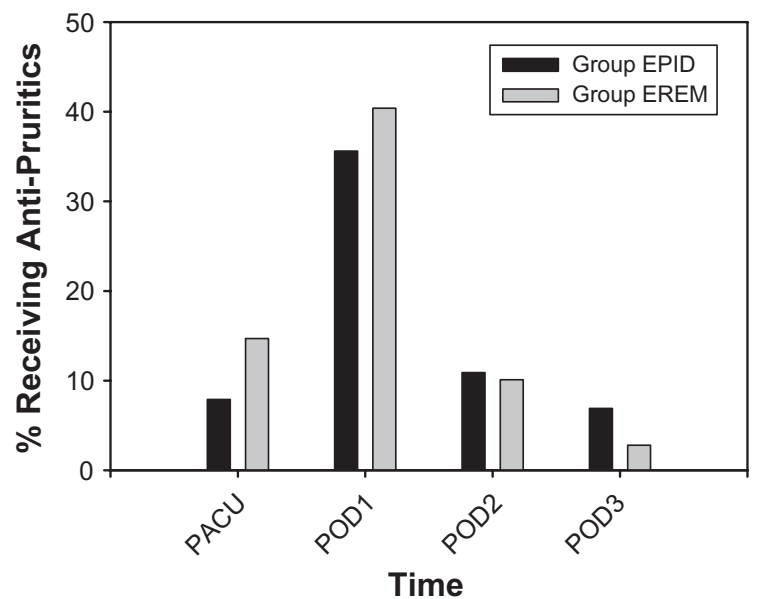

Figure 4 Percentage of subjects receiving postoperative antipruritics.

Notes: The proportion of subjects receiving antipruritics postoperatively was similar in Groups EREM and EPID.

Abbreviations: Group EPID received a continuous epidural infusion of morphine; Group EREM received a single epidural injection of extended-release morphine; PACU, post anesthesia care unit; POD, postoperative day.

The current results identified an "analgesic gap" among patients who received a continuous epidural infusion of morphine. An analgesic gap is defined as a decrease in analgesic effectiveness during the period of transition between pain management modalities and this can result from a number of different factors. ${ }^{17-20}$ In the current study, the analgesic gap might be the result of a breakdown in the "system", as pain management responsibilities were transferred from the Acute Pain Service to the Orthopedic Service after the continuous epidural infusion was discontinued and the epidural catheter removed. An analgesic gap did not occur among patients who received extended-release epidural morphine, perhaps because pain management responsibilities were with the Orthopedic Service throughout the study period. Communication failures occur frequently among health care providers and are a common source of adverse events, including such analgesic gaps. ${ }^{18,21}$ Alternative explanations for the analgesic gap after discontinuation of the epidural infusion include delays in implementing drug orders, rebound pain or even opioid-induced hyperalgesia. ${ }^{22} \mathrm{~A}$ follow-up study has been implemented to identify the cause(s) of the analgesic gap at our institution.

In terms of side effects, subjects who received extended-release epidural morphine had higher rates of nausea and respiratory depression than subjects who received a continuous epidural infusion of morphine. In the current study, the estimated incidence of respiratory depression after extended-release epidural morphine was close to $5 \%$. Cases of respiratory depression requiring treatment with a narcotic 

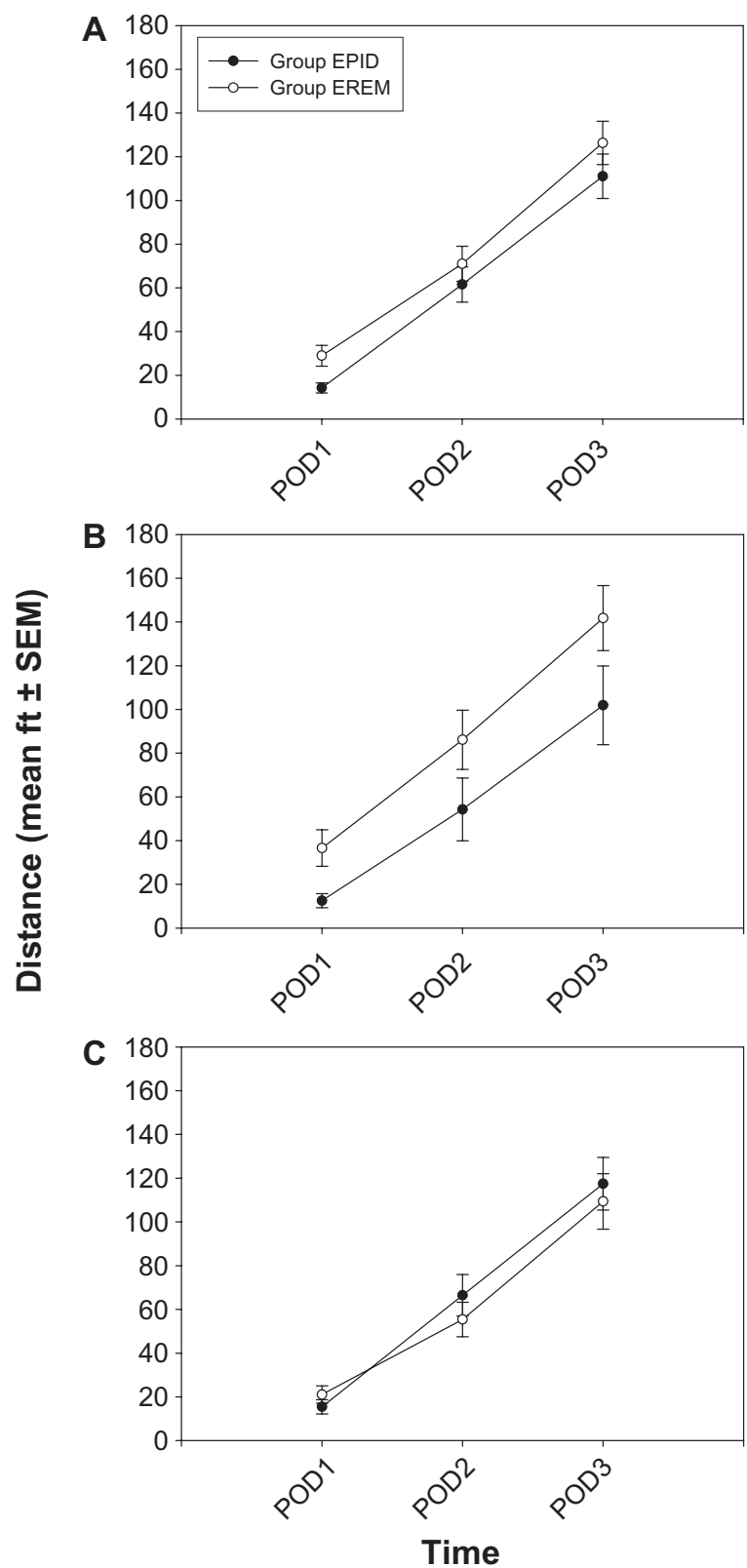

Figure 5 Maximum distance ambulated in feet (mean \pm SEM) during postoperative physical therapy.

Notes: Subjects in Group EREM ambulated a greater distance than those in Group EPID at all time points $(P<0.05$; panel $\mathbf{A})$. However, when subjects were stratified by surgical subset, the group difference was evident only in total hip arthroplasty subjects $(P<0.05$; panel B), not in total knee arthroplasty subjects (panel $\mathbf{C}$ ).

Abbreviations: Group EPID received a continuous epidural infusion of morphine; Group EREM received a single epidural injection of extended-release morphine; PACU, post anesthesia care unit; POD, postoperative day.

antagonist have been reported in $4 \%-8 \%$ of subjects receiving extended-release epidural morphine (DepoDur ${ }^{\circledR}$ ) for total joint replacement surgery. ${ }^{10-12}$ Because of the risk of respiratory depression, the continuous monitoring of vital signs is recommended for all patients who receive extended-release epidural morphine. ${ }^{23-25}$ The current results support this recommendation.
Ambulatory function was greater among subjects who received extended-release epidural morphine than among those who received a continuous epidural infusion of morphine, perhaps because of the ease of ambulation without the infusion pump. However, the effect was found only in the THA subset. The reason(s) why similar results were not found in the TKA subset is unclear, although it might reflect the different approaches taken by physical therapists for rehabilitation after THA versus TKA. ${ }^{6}$ For instance, patients who undergo THA may be more encouraged to ambulate postoperatively than patients who undergo TKA.

\section{Limitations}

Several limitations of this study should be considered when interpreting the results. First, this was a retrospective study and as such, it is vulnerable to several forms of bias. Second, the primary data sources were nursing and physical therapy records, and nurses and physical therapists were not specifically trained for data collection, making measurement error possible. Third, the two groups were not identical in their demographic characteristics. In particular, subjects in Group EREM were older than subjects in Group EPID, and this age difference might have influenced the results. Fourth, factors other than pain are known to influence ambulation after TKA and THA, including numbness, weakness, hypovolemia and other factors that were not examined. Fifth, although TKA and THA are relatively standardized procedures and the same two surgeons performed the operations throughout the study period, variations in surgical technique could have been introduced confounding the data. Sixth, baseline pain scores are known to influence postoperative pain ${ }^{26}$ and this was not accounted for in the present study. Finally, the two pain management approaches that were compared were not strictly standardized and variation in technique existed within the groups.

\section{Conclusions}

In summary, continuous epidural infusion of morphine and single epidural injection of extended-release morphine provided similar levels of pain control, although the transition to oral or intravenous analgesics resulted in an analgesic gap among subjects in the continuous epidural infusion group. This analgesic gap is likely related to a system issue, rather than the analgesic technique itself. Patients who received extended-release epidural morphine experienced higher levels of respiratory depression and nausea, although a better return to function, at least after THA. Further prospective studies comparing these two pain 
management approaches are warranted before treatment recommendations can be made.

\section{Acknowledgments}

The authors wish to acknowledge Ryan Gardner for assistance with data collection and Natalie Miller for assistance with data entry. The authors also wish to acknowledge Dr. Monika Nanda for critical review of the manuscript.

\section{Disclosure}

The authors report no conflicts of interest relevant to this research.

\section{References}

1. Archibeck MJ, White RE. What's new in adult reconstructive knee surgery. J Bone Joint Surg Am. 2006;88:1677-1686.

2. Huo MH, Parvizi J, Bal S, Mont MA. What's new in total hip arthroplasty. J Bone Joint Surg Am. 2008;90:2043-2055.

3. Birrel F, Johnell O, Silman A. Projecting the need for hip replacement over the next three decades: Influence of changing demography and threshold for surgery. Ann Rheum Dis. 1999;58:569-572.

4. National Center for Health Statistics, Center for Disease Control. Health, United States, 2006. Available from: http://www.cdc.gov/nchs/data/hus/ hus06.pdf Accessed Apr 2010.

5. Ranawat AS, Ranawat CS. Pain management and accelerated rehabilitation for total hip and total knee arthroplasty. $J$ Arthroplasty. 2007;22:12-15.

6. Meier W, Mizner R, Marcus R, Dibble L, Peters C, Lastayo PC. Total knee arthroplasty: Muscle impairments, functional limitations, and recommended rehabilitation approaches. J Orthop Sports Phys Ther. 2008;38:246-256.

7. Capdevila X, Barthelet Y, Biboulet P, Ryckwaert Y, Rubenovitch J, d'Athis F. Effects of perioperative analgesic technique on the surgical outcome and duration of rehabilitation after major knee surgery. Anesthesiology. 1999:91:8-15.

8. Kehlet H, Holte K. Effect of postoperative analgesia on surgical outcome. Br J Anaesth. 2001;87:62-72.

9. Singelyn FJ, Deyaert M, Pendeville E, Gouverneur JM. Effects of intravenous patient-controlled analgesia with morphine, continuous epidural analgesia, and continuous three-in-one block on postoperative pain and knee rehabilitation after unilateral total knee arthroplasty. Anesth Analg. 1998;87:88-92.

10. Gambling D, Hughes T, Martin G, Horton W, Manvelian G. A comparison of Depodur ${ }^{\mathrm{TM}}$, a novel, single-dose extended-release epidural morphine, with standard epidural morphine for pain relief after lower abdominal surgery. Anesth Analg. 2005;100:1065-1074.
11. Hartrick CT, Martin G, Kanotr G, Koncelik J, Manvelian G. Evaluation of a single-dose, extended-release epidural morphine formulation for pain after knee arthroplasty. J Bone Joint Surg Am. 2006;88:273-281.

12. Viscusi ER, Martin G, Hartrick CT, Singla N, Manvelian G. Forty-eight hours of postoperative pain relief after total hip arthroplasty with a novel, extended-release epidural morphine formulation. Anesthesiology. 2005;102:1014-1022.

13. Singelyn FJ, Ferrant T, Malisse MF, Joris D. Effects of intravenous patient-controlled analgesia with morphine, continuous epidural analgesia, and continuous femoral nerve sheath block on rehabilitation after unilateral total-hip arthroplasty. Reg Anesth Pain Med. 2005;30:452-457.

14. Gutstein HB, Akil H. Opioid analgesics. In: Gilman AG, Hardman JG, Limbird, LE, editors. Goodman \& Gilman's The Pharmacological Basis of Therapeutics, 10th ed. New York, NY: McGrawHill; 2001. p 569-620.

15. Dhesi SS, Hurley RW. The neurobiology of pain. In: Tollison CD, Satterthwaite JR, Tollison JW, editors. Practical Pain Managemen. 3rd ed. Philadelphia, PA: Lippincott Williams \& Wilkins; 2002:1-25.

16. de Leon-Casasola OA, Parker B, Lema MJ, Harrison P, Massey J. Postoperative epidural bupivacaine-morphine therapy: Experience with 4,227 surgical cancer patients. Anesthesiology. 1994;81:368-375.

17. Smith G, Power I. Audit and bridging the analgesic gap. Anaesthesiology 1998;53:521-522.

18. Ng A, Hall F, Atkinson A, Kong KL, Hahn A. Bridging the analgesic gap. Acute Pain. 2000;3:194-199.

19. Carr DB, Reines HD, Schaffer J, Polomano RC, Lande S. The impact of technology on the analgesic gap and quality of acute pain management. Reg Anesth Pain Med. 2005;30:286-291.

20. Panchal SJ, Damaraju CV, Nelson WW, Hewitt DJ, Schein JR. System-related events and analgesic gaps during postoperative pain management with the fentanyl iontophoretic transdermal system and morphine intravenous patient-controlled analgesia. Anesth Analg. 2007;105:1437-1441.

21. Kohn LT, Corrigan JM, Donaldson MS, editors. Committee on quality of healthcare in America, Institute of Medicine. To err is human: Building a safer health system. Washington, DC: National Academies Press; 2000.

22. Angst MS, Clark JD. Opioid-induced hyperalgesia: A qualitative systematic review. Anesthesiology. 2006;104:570-587.

23. Angst MS, Drover DR. Pharmacology of drugs formulated with DepoFoam $^{\mathrm{TM}}$ : A sustained release drug delivery system for parenteral administration using multivesicular liposome technology. Clin Pharmacokinet. 2006;45:1153-1176.

24. Keck S, Glennon C, Ginsberg B. DepoDur ${ }^{\circledR}$ extended-release epidural morphine: Reshaping postoperative care. What perioperative nurses need to know. Orthopaed Nurs. 2007;26:86-93.

25. Rathmell JP, Wu CL, Sinatra RS, et al. Acute post-surgical pain management: A critical appraisal of current practice. Reg Anesth Pain Med. 2006;131:1-42.

26. Kehlet H, Jensen TS, Woolf CJ. Persistent postsurgical pain: Risk factors and prevention. Lancet. 2006;367:1618-1625.
Therapeutics and Clinical Risk Management

\section{Publish your work in this journal}

Therapeutics and Clinical Risk Management is an international, peerreviewed journal of clinical therapeutics and risk management, focusing on concise rapid reporting of clinical studies in all therapeutic areas, outcomes, safety, and programs for the effective, safe, and sustained use of medicines. This journal is indexed on PubMed Central, CAS,

\section{Dovepress}

EMBase, Scopus and the Elsevier Bibliographic databases. The manuscript management system is completely online and includes a very quick and fair peer-review system, which is all easy to use. Visit http://www.dovepress.com/testimonials.php to read real quotes from published authors. 